\title{
Detection of outer raceway bearing defects in small induction motors using stator current analysis
}

\author{
IZZET Y ÖNEL*, K BURAK DALCI and IBRAHIM SENOL \\ Yildiz Technical University, Electrical-Electronics Faculty, Electrical Engineering \\ Department, 34349 Besiktas-Istanbul, Turkey \\ e-mail: \{ionel, dalci, senol $\} @$ yildiz.edu.tr
}

MS received 10 February 2005; revised 22 July 2005

\begin{abstract}
We investigate the application of induction motor stator current spectral analysis (MCSA) for detection of rolling element bearing damage from the outer raceway. In this work, MCSA and vibration analysis are applied to induction motor to detect outer raceway defects in faulty bearings. Data acquisition, recording, and fast fourier transform (FFT) algorithms are done by using the LabVIEW programming language. Experimental results verify the relationship between vibration analysis and MCSA, and identify the presence of outer raceway bearing defects in induction machines. This work also indicates that detecting fault frequencies by motor currents is more difficult than detecting them by vibration analysis. The use of intensive resolution FFT is recommended in MCSA for detecting faults easily. Reinstalling a faulty bearing can alter the characteristic frequencies and it is difficult to compare results from different bearings or even from the same bearing in different installations.
\end{abstract}

Keywords. Motor vibration; spectral analysis; stator current; bearing damage.

\section{Introduction}

Induction motors are frequently used in industrial applications in a wide range of operating areas, due to their simple and robust structure and low production cost. The reliability of an induction motor is of paramount importance in industrial, commercial, aerospace and military applications. Bearings play an important role in the reliability and performance of all motor systems. Due to the close relationship between motor system development and bearing assembly performance, it is difficult to imagine the progress of modern rotating machinery without consideration of the wide application of bearings. In addition, most faults arising in motors are often linked to bearing faults. The result of many studies show that bearing problems account for over $40 \%$ of all machine failures (Schoen et al 1995).

In many situations, vibration monitoring methods are utilized to detect the presence of an incipient bearing failure. Vibration monitoring is a reliable tool for detecting bearing

\footnotetext{
*For correspondence

A list of symbols is given at the end of the paper
} 
failures. Vibration data typically contain fault signatures and salient fault features because of direct measurement of the critical signal and placement of the vibration sensor. However, placing a sensing device on the motor might not be possible or practical in many applications, especially for a facility that employs a large number of electrical machines. In military and aerospace areas, large electromechanical systems are often equipped with mechanical sensors, primarily vibration sensors based on proximity probes. These are delicate, and too expensive for industrial systems, and can cause heavy loss to the customer. This is why, in spite of the existence of vibration methods, it has been suggested that stator current monitoring can provide the same information without requiring access to the motor body (Anon 1992). On the other hand, stator current is readily available in many applications, and is usually measured for motor protection. Therefore, current-based fault detection has become an attractive means of bearing-condition monitoring. Many papers have been published presenting methods for indication of these faults by use of stator current measurement (Benbouzid et al 1999; Kliman \& Stein 1990; Levent \& Devaney 2001; Lindh et al 1999; Riley et al 1999; Schoen et al 1995; Yazıcı \& Kliman 1999).

In the present paper, some experiments are presented using motor current signature analysis (MCSA) that clarify some of the factors that may effect the indication of outer race defects of ball bearings by using the fast fourier transform to the stator current. Also, this paper demonstrates the feasibility of this detection method by correlating the characteristic-bearing frequencies to the spectral components of the stator current. Test results showing the vibration and current spectra are used to clearly exhibit this relationship.

This work indicates that detecting these fault frequencies in the motor current is significantly more difficult than detecting them in the motor vibration. Additionally, installing a test bearing in a test motor can significantly alter the current and vibration characteristics of the machine owing to reassembling and realigning of the motor and dynamo. Therefore, it is difficult to compare different bearings of the same type or even the same bearing in different installations.

\section{Bearing structural defects}

Rolling element bearings generally consist of two rings, an inner and an outer, between which a set of balls or rollers rotate in raceways. Under normal operating conditions of balanced load and good alignment, fatigue failure begins with small fisures, located between the surface of the raceway and the rolling elements, which gradually propagate to the surface generating detectable vibrations and increasing noise levels (Eschmann et al 1958). Continued stress causes fragments of the material to break loose, producing a localized fatigue phenomena known as flaking or spalling (Riddle 1955). Once started, the affected area expands rapidly contaminating the lubricant and causing localized overloading over the entire circumference of the raceway (Eschmann et al 1958). Eventually, the failure results in rough running of the bearing. While this is the normal mode of failure in rolling element bearings, there are many other conditions which reduce the time to bearing failure. These external sources include contamination, corrosion, improper lubrication, improper installation or brinelling.

Contamination and corrosion frequently accelerate bearing failure because of the harsh environments present in most industrial settings. Dirt and other foreign matter that is commonly present often contaminate the bearing lubrication. The abrasive nature of this minute particles, whose hardness can vary from relatively soft the diamond like, cause pitting and sanding actions that give way to measurable wear of the balls and raceways (Riddle 1955). 


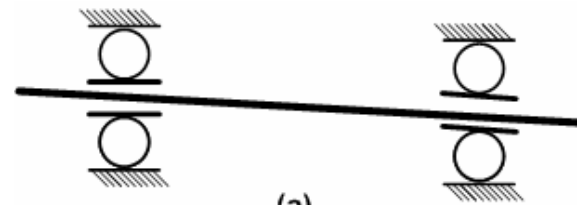

(a)

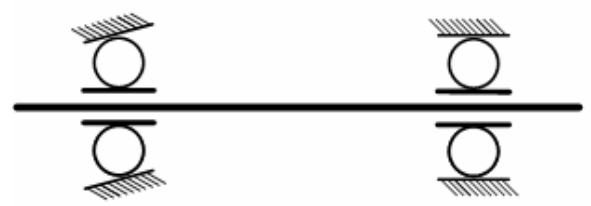

(c)

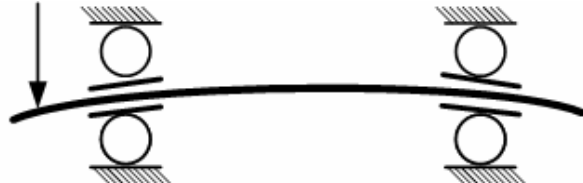

(b)

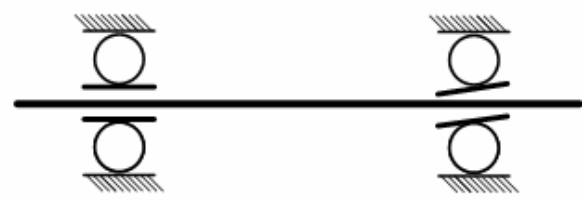

(d)

Figure 1. (a) Misalignment (out-of-line), (b) Shaft deflection, (c) crooked or tilted outer race, (d) crooked or tilted inner race.

Bearing corrosion is produced by the presence of water, acids, deteriorated lubrication and even perspiration from careless handling during installations (Eschmann et al 1958; Riddle 1955). Once the chemical reaction has advanced sufficiently, particles are worn-off resulting in the same abrasive action produced by bearing contamination. Improper lubrication includes both under- and over-lubrication. In either case, the rolling elements are not allowed to rotate on the designed oil film causing increased levels of heating. The excessive heating causes the grease to break down, which reduces its ability to lubricate the bearing elements and accelerates the failure process.

Installation problems are often caused by improperly forcing the bearing onto the shaft or in the housing. This produces physical damage in the form of brinelling or false brinelling of the raceways which leads to premature failure. Misalignment of the bearing, which occurs in the four ways depicted in figure 1, is also a common result of defective bearing installation. The most common of these is caused by tilted races (Riddle 1955).

Brinelling is the formation of indentations in the raceways as a result of deformation caused by static overloading. While this form of damage is rare, a form of "false brinelling" occurs more often. In this case, the bearing is exposed to vibrations while even though lightly loaded bearings are less susceptible, false brinelling still happens and has even occurred during the transportation of uninstalled bearings (Eschmann et al 1958).

Regardless of the failure mechanism, defective rolling element bearings generate mechanical vibrations at the rotational speeds of each component. These characteristic frequencies, which are related to the raceways and the balls or rollers, can be calculated from the bearing dimensions and the rotational speed of the machine. Mechanical vibration analysis techniques are commonly used to monitor these frequencies in order to determine the condition of the bearing.

\section{Stator current analysis}

The relationship of the bearing vibration to the stator current spectrum can be determined by remembering that any air-gap eccentricity produces anomalies in the air-gap flux density. In the case of a dynamic eccentricity that varies with rotor position, the oscillation in the air-gap 
Table 1. Fault frequencies for bearing damage.

\begin{tabular}{ll}
\hline Cage fault & $f_{c}=\frac{1}{2} f_{r}\left(1-\frac{D_{B} \cos \theta}{D_{P}}\right)$ \\
Outer raceway fault & $f_{o}=\frac{N_{B}}{2} f_{r}\left(1-\frac{D_{B} \cos \theta}{D_{P}}\right)$ \\
Inner raceway fault & $f_{i}=\frac{N_{B}}{2} f_{r}\left(1+\frac{D_{B} \cos \theta}{D_{P}}\right)$ \\
Ball fault & $f_{b}=\frac{D_{P}}{2 D_{B}} f_{r}\left(1-\frac{D_{B}^{2} \cos ^{2} \theta}{D_{P}^{2}}\right)$ \\
\hline
\end{tabular}

length causes variations in the air-gap flux density. This variation affects the inductance of the machine producing stator current harmonics with frequencies predicted by

$$
f_{e c c}=f_{e}\left[1 \pm k\left(\frac{1-s}{p / 2}\right)\right], \quad f_{e c c}=\left|f_{e} \pm k \cdot f_{r m}\right|,
$$

where $f_{e}$ is the electrical supply frequency, $k=1,2,3, \ldots, s$ is the per unit slip, $p$ is the number of machine pole pairs and $f_{r m}$ is the mechanical rotor speed in hertz.

Since ball bearings support the rotor, any bearing defect produces a radial motion between the rotor and the stator of the machine. The cause of air-gap eccentricity, these variations generate harmonic stator currents at predictable frequencies, related to the vibrational and electrical supply frequencies by

$$
f_{\text {bng }}=\left|f_{e} \pm m \cdot f_{v}\right|,
$$

where $m=1,2,3, \ldots$ and $f_{v}$ is one of the characteristic vibration frequencies. These fault frequencies are given in table 1 , where $N_{B}$ is the number of balls, $D_{B}$ is the ball diameter, $D_{P}$ is the ball pitch diameter, $\theta$ is the ball contact angle (typically equals $0^{\circ}$ ) and $f_{r}$ is relative revolution per second between inner and outer races. These equations, shown in table 1, require specific information concerning the bearing construction to calculate the exact characteristic frequencies.

In the case of bearings with between six and twelve rolling elements, the fundamental inner and outer race frequencies, $f_{i}$ and $f_{o}$, can be calculated approximately by,

$$
f_{i}=0 \cdot 6 \cdot N_{B} \cdot f_{r m}, \quad f_{o}=0.4 \cdot N_{B} \cdot f_{r m} .
$$

In this way it is possible to determine the bearing race frequencies for all seven ball combinations without having explicit knowledge of the bearing construction. This allows determination of the important frequency components in the stator current and these frequency values are defined as $f_{e} \pm 0 \cdot 4 \cdot N_{B} \cdot f_{r m}$ and $f_{e} \pm 0 \cdot 6 \cdot N_{B} \cdot f_{r m}$, where $N_{B}=6,7, \ldots, 12$ (Schoen et al 1995).

\section{System information}

\subsection{Stator current monitoring system}

The purpose of the monitoring system is to measure the induction motor stator current and to analyse these data determining the vibration frequencies on the bearing. The currents that 
Table 2. Rated parameters of the machine under test.

\begin{tabular}{lcc}
\hline Power & 0.75 & $\mathrm{~kW}$ \\
Frequency & 50 & $\mathrm{~Hz}$ \\
Voltage $(\Delta / Y)$ & $220 / 380$ & $\mathrm{~V}$ \\
Current $(\Delta / Y)$ & $3.4 / 1.95$ & $\mathrm{~A}$ \\
Speed & 2780 & $\mathrm{rpm}$ \\
Pole pair $(p)$ & 1 & \\
\hline
\end{tabular}

flow in the three phases of the induction motor are sensed by a current transformer and the velocity information of induction motor are sent to the National Instruments PCI-1200 data acquisition card that is connected to the PCI slot of a personal computer. The digitalised current signal is applied to the low pass current filter to remove the undesirable high frequency components that produce aliasing of the sampled signal. The LabVIEW programme converts the sampled signal whose frequency is $10 \mathrm{ksample} / \mathrm{s}$, to the frequency domain using a fast Fourier transform (FFT) algorithm. The current spectrum is generated by the FFT algorithm with 4096 points and includes only the magnitude information for each frequency component. For decreasing the signal noise in current spectrum, the FFT algorithm is calculated ten times and the average value of this calculation is evaluated in the fault detection algorithm.

\subsection{Testing equipment}

In this study, a $0.75 \mathrm{~kW}$ two-pole induction motor AGM $802 \mathrm{~A}$, with parameters as given in table 2 , was used.

The nominal current is $I_{N}=1.95 \mathrm{~A}$ when star-connected to $380 \mathrm{~V}$ network. The motor is loaded with car alternator VDN10701118 whose $12 \mathrm{~V} \mathrm{DC}$ output is applied to the variable resistive loads. The alternator, tacho generator and induction motor are connected together with steel coupling in the same alignment. The analogue tacho generates $90 \mathrm{~V}$ at $3000 \mathrm{rpm}$. The testing equipment is illustrated in figure 2.

The bearings of the induction motor are single row, deep groove ball bearings, type 6204.2ZR. Each bearing has 8 balls. Experiments were conducted on 5 bearings: one of these is undamaged, while four bearings were drilled through the outer race with holes of diameters between 3 and $6 \mathrm{~mm}$ as illustrated in figure 3 .

\section{Measurement configuration}

Stator current was measured on all three phases with current transformers at a rate of $5 / 1$. The velocity of the induction motor is handled with analog tacho generator $(0 \cdot 03 \mathrm{~V} / \mathrm{rpm})$. In addition, radial vibration was measured with a piezzoelectric acceletrometer. The measurement configuration is illustrated in figure 4. Induction motor currents and tacho generator output are digitalised with the National Instrument's data acquisition card called PCI-1200. The 1200 family devices are low cost, multifunction I/O devices with up to $100 \mathrm{kS} / \mathrm{s}, 12$-bit performance on 8 single-ended or 4 differential analogue inputs. The 1200 family features digital triggering capability; three 16-bit, $8 \mathrm{MHz}$ counter/timers; two 12-bit analogue outputs; 


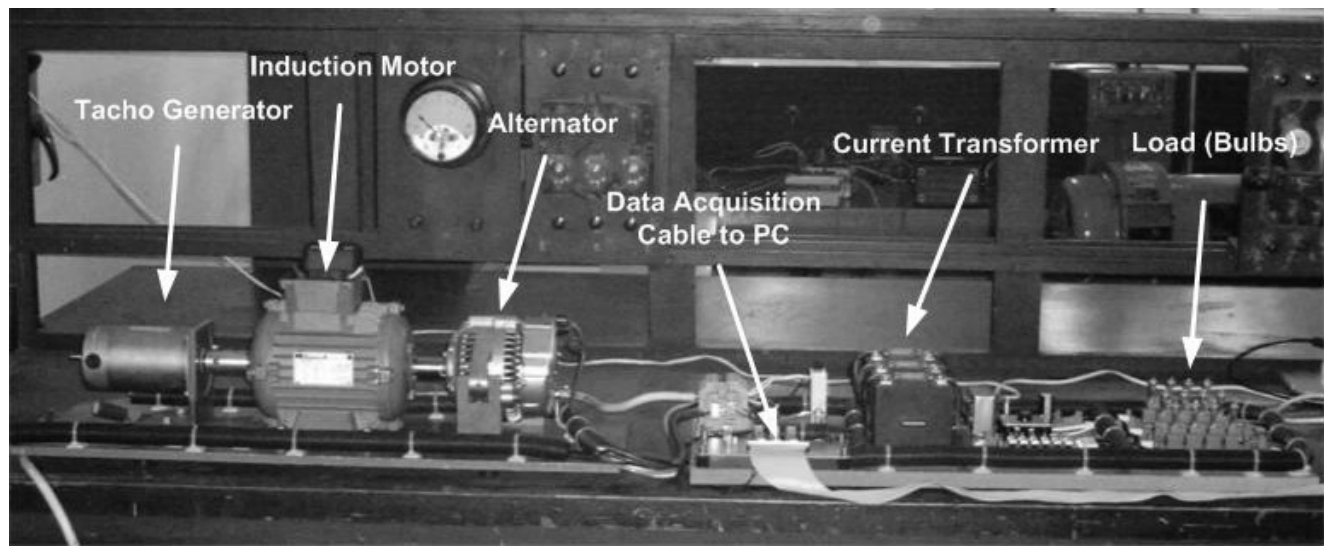

Figure 2. Test jig has two parts: Mechanical and electrical. Mechanical part consists of a tacho generator for speed measuring and an induction motor with bearing failure, and a car alternator to load the induction motor. Electrical part of the test jig has three parts: three current transformers, an outlet to the PC-based data acquisition card and bulbs that are used as loads.

and 24 digital I/O lines (National Instruments 1998). The proposed LabVIEW programme takes in a signal and performs an FFT algorithm, including measuring the fundamental frequency tone, other harmonics, returns the fundamental frequency and all harmonic amplitude levels, and records this knowledge in the computer environment.

\subsection{Experimental study}

In the Electrical Machines Laboratory of Y1ldiz Teknik University, ten bearings of 6204.2ZR type were damaged by drilling holes of different sizes such as $3,4,5,6 \mathrm{~mm}$ respectively completely through the outer races. While these are not realistic bearing failures, the artificial bearing faults produce characteristic fault frequencies and the type of fault is determined by vibration or current spectra. The fault on the raceway affects the air-gap displacement in the radial direction and the radial vibration is measured at the bearing using a charge-type piezoelectric accelerometer.

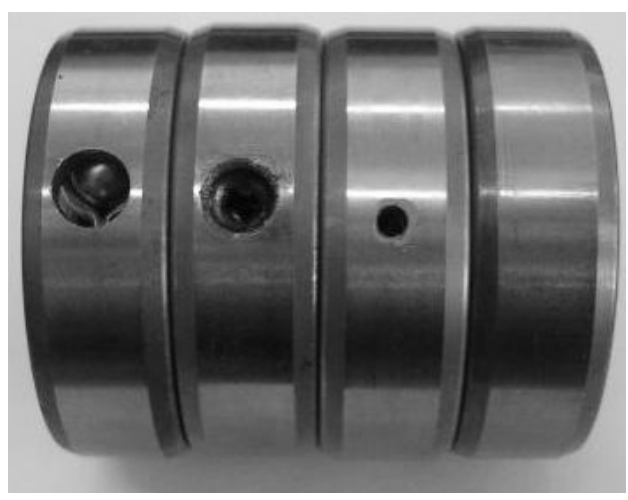

Figure 3. Three bearings with holes drilled through the outer race and an intact bearing. 


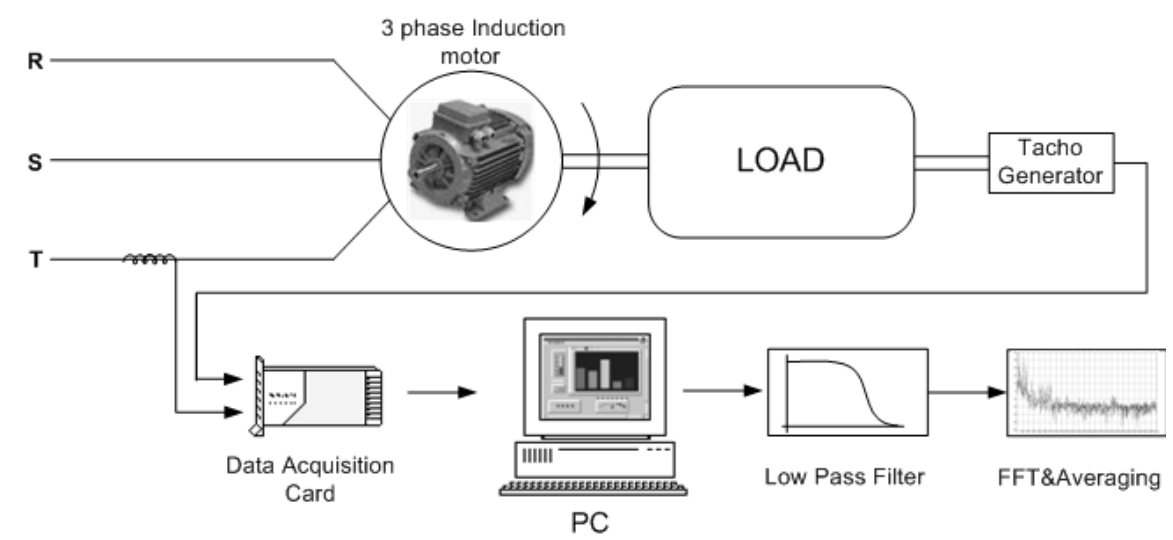

Figure 4. Measurement configuration block diagram.

Bearings of type 6204.2ZR were made to fail by drilling holes of various radii with a diamond twist bit while controlling temperature by oil circulation, in experiments and were installed on a $0.75 \mathrm{~kW}$, two-pole induction motor. From the bearing data sheet, the outside diameter of a $6204.2 \mathrm{ZR}$ bearing is $47 \mathrm{~mm}$ and inside diameter is $20 \mathrm{~mm}$. Assuming that the inner and the outer races have the same thickness gives the pitch diameter as equal to $31.85 \mathrm{~mm}$ $\left(D_{P}=31.85 \mathrm{~mm}\right)$. The bearing has eight balls $(N=8)$ with approximate diameters of $12 \mathrm{~mm}\left(D_{B}=12 \mathrm{~mm}\right)$. Assuming a contact angle $\theta=0^{\circ}$ and motor operation at a rated shaft speed of $2780 \mathrm{rpm}$, the characteristic race frequencies of the shaft-end bearing are calculated from (3) as $f_{o}=157 \mathrm{~Hz}$ for the loaded motor. This frequency value is based upon the assumptions described above, the actual frequency is approximated to the calculated value of the bearing.

The results show that for a bearing which was damaged from the outer raceway by a $4 \mathrm{~mm}$ width hole, the characteristic frequencies could not be seen in the current in spite of salient faults being visible on the vibration spectrum. The vibration and the current spectra of the bearing that has a drilled hole of width $4 \mathrm{~mm}$ are shown in figure 5 .

Other bearings that were made to fail by drilling holes of 5 and $6 \mathrm{~mm}$ diameter completely from the outer race are shown in figure 3 . At the conclusion of the experiment, outer race characteristic frequencies were detectable in the vibration spectra and the corresponding current harmonic components were visible in the current spectra as well.

Figures $6 \mathrm{a}-\mathrm{c}$ show the comparative vibration spectra of a loaded 2-pole induction machine, healthy bearing and defective bearing with a $5 \mathrm{~mm}$ width hole. Characteristic vibration frequency values $2 \cdot f_{o}, 3 \cdot f_{o}$ and $5 \cdot f_{o}$ as shown in the plots are clearly evident. Logarithmic plots of the current spectra are shown in figures $5 \mathrm{~d}-\mathrm{f}$ and the corresponding current components are visible in the current spectra $\left|f_{e}-2 \cdot f_{o}\right|=264,\left|f_{e}-3 \cdot f_{o}\right|=$ $421,\left|f_{e}+3 \cdot f_{o}\right|=521,\left|f_{e}-5 \cdot f_{o}\right|=735$ and $\left|f_{e}+5 \cdot f_{o}\right|=835 \mathrm{~Hz}$ frequencies, as proved in (2) earlier. It is shown that these components are visible only in the plots of the defective bearing.

Current and vibration measurements for the damaged bearings were repeated under unloaded operation of the induction machine. The effect of the loading can be seen in the vibration spectra in figure $7 \mathrm{a}$. The amplitudes of the bearing vibrations have decreased because of the damping produced by the mechanical load. The current harmonics predicted 


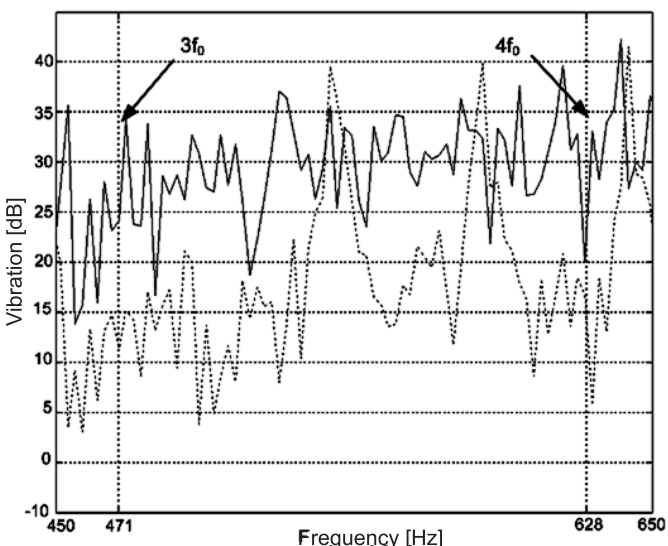

(a)

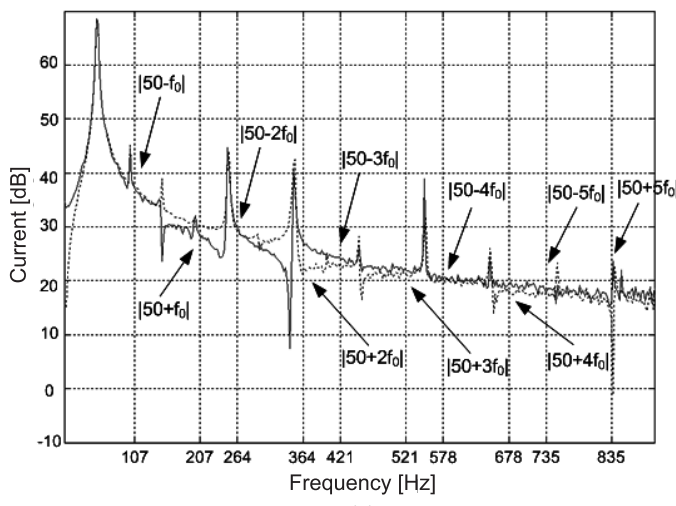

(c)

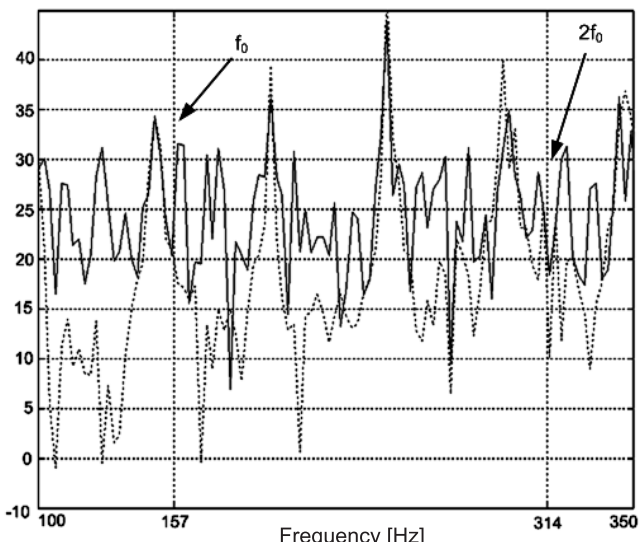

(b)

Figure 5. Comparison of the vibrations $(\mathbf{a}, \mathbf{b})$ and current spectra (c) of a loaded 2-pole induction machine, healthy bearing and defective bearing with a $4 \mathrm{~mm}$ width hole.

for rated speed operation can still be found in the current spectrums as shown in figure $7 \mathrm{~b}$. This indicates that, regardless of the load level of the machine, the bearing components are still detectable in the current spectrum. It is important to note that the frequency components produced by the bearing defect are relatively small when compared to the rest of the current spectrum. The largest components present in the current spectra occur at multiples of the supply frequency and are caused by saturation, winding distribution and supply voltage. This large difference in magnitude can make detection of the current spectrum bearing harmonics a significant problem.

\section{Conclusions}

This paper has investigated the feasibility of detecting bearing faults using the spectrum of a single phase of the stator current of an induction machine. Defective rolling element bearings generate eccentricity in the air-gap with mechanical vibrations. The air-gap eccentricities cause variations in the air-gap flux density that produces visible changes in the stator current spectrum. Experimental results which show the vibration and current spectra of an induction 

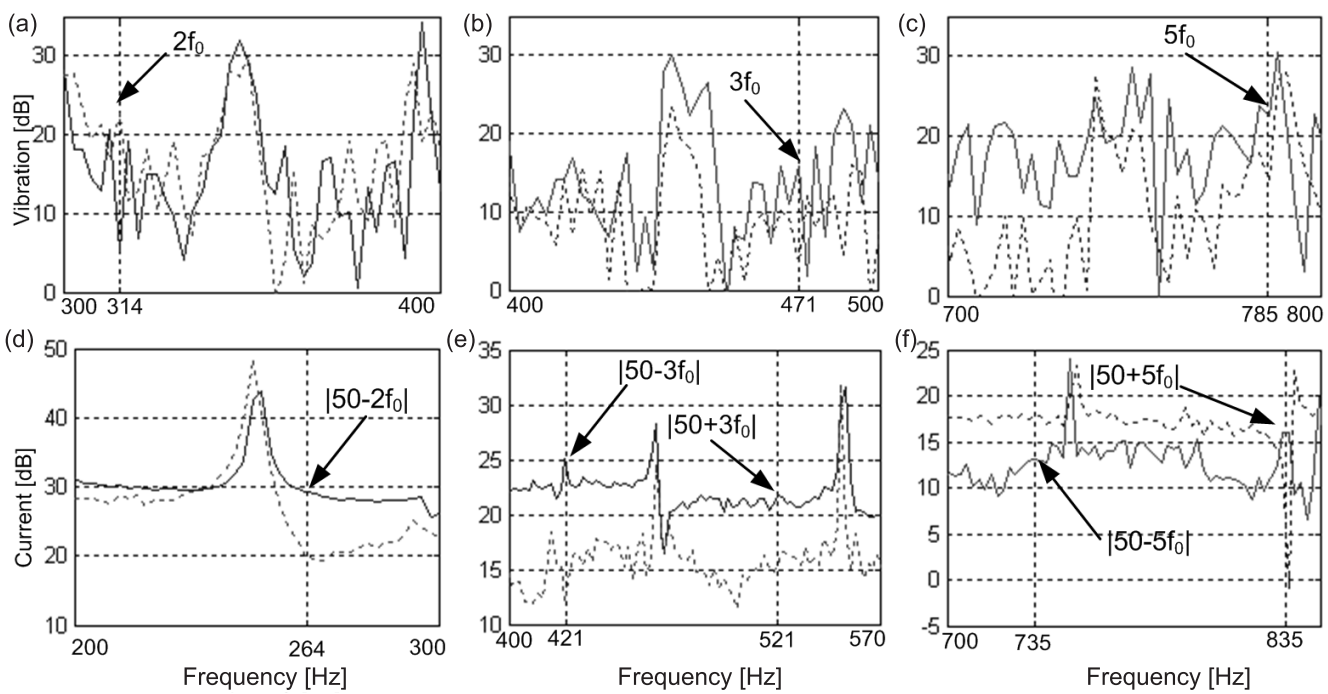

Figure 6. Comparison of the vibration and current spectra of a loaded 2-pole induction machine healthy bearing and defective bearing with $5 \mathrm{~mm}$ width hole (dotted line: healthy bearing; bold line: defective bearing).

machine with outer race defects are used to verify the relationships between the vibrational and current frequencies. The experimental results clearly illustrate that the stator current signature can be used to identify the presence of a bearing fault.

This research also indicates that detecting these fault frequencies in the motor current is significantly more difficult than detecting them in the motor vibration. For this reason, the use of wider frequency ranges in the fast Fourier transform is recommended for current-based detection. Additionally, the act of installing or remounting a test bearing in a test motor can alter the current and vibration characteristics of the induction machine and conceal some fault frequencies; therefore, it is difficult to compare different bearings of the same type or even the same bearing in different installations.
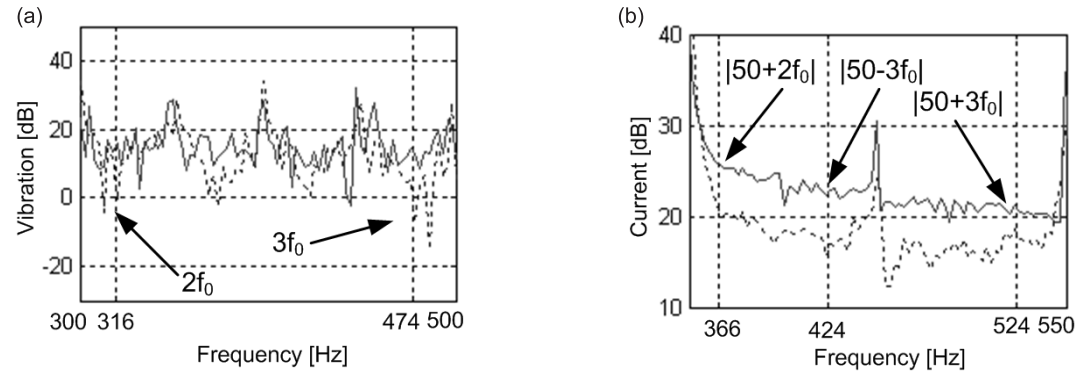

Figure 7. Comparison of the vibration (a) and current (b) spectra of an unloaded 2-pole induction machine, healthy bearing and defective bearing with $5 \mathrm{~mm}$ width hole. 


\section{List of symbols}

$D_{B} \quad$ ball diameter (mm);

$D_{P} \quad$ ball pitch diameter $(\mathrm{mm})$;

$f_{B} \quad$ ball defect characteristic frequency $(\mathrm{Hz})$;

$f_{b n g} \quad$ harmonic stator currents;

$f_{C} \quad$ cage defect characteristic frequency $(\mathrm{Hz})$;

$f_{e} \quad$ electrical supply frequency $(\mathrm{Hz}) ;$

$f_{e c c}$ eccentricity frequency $(\mathrm{Hz})$;

$f_{i} \quad$ inner race defect characteristic frequency $(\mathrm{Hz})$;

$f_{o} \quad$ outer race defect characteristic frequency $(\mathrm{Hz})$;

$f_{r} \quad$ relative revolutions per second between inner and outer races $(\mathrm{Hz})$;

$f_{r m}$ mechanical rotor speed $(\mathrm{Hz})$;

$f_{v} \quad$ characteristic vibration frequencies $(\mathrm{Hz})$;

$N_{B} \quad$ number of balls;

$p \quad$ the number of machine pole pairs;

$s \quad$ slip (pu);

$\beta \quad$ contact angle of balls to inner and outer races.

\section{References}

Anon 1992 Methods of motor current signature analysis. Elec. Mach. Power Syst. 20: 463-474

Benbouzid M E H, Vieira M, Theys C 1999 Induction motor' fault detection and localisation using stator current advanced signal processing techniques. IEEE Trans. Power Electron. 14: 147-152

Eschmann P, Hasbargen L, Weigand K 1958 Ball and roller bearings: Their theory, design, and application (London: K G Heyden)

Kliman G B, Stein J 1990 Induction motor fault detection via passive current monitoring. In Proc. Int. Conf. Electrical Machinery, Cambridge, pp 13-17

Kliman G B, Stein J 1992 Methods of motor current signature analysis. Elec. Mach. Power Syst. 20: 463-474

Levent E, Devaney M J 2001 Motor bearing damage detection via wavelet analysis of the starting current moment. IEEE Instrumentation and Measurement Technology Conference (New York: IEEE Press)

Lindh T, Ahola J, Partanen J 2002 Evaluation of condition monitoring of bearings of $15 \mathrm{~kW}$ induction motor based on statistical stator current analysis. In Proc. Int. Conf. on Electrical Machines, Brugges, Belgium (CD-ROM)

National Instruments 1998 Data acquisition basics manual

Riddle J 1955 Ball bearing maintenance (Norman, OK: Univ. of Oklohama Press)

Riley C M, Lin B K, Habetler T G, Kliman G B 1999 Stator current harmonics and their causal vibraitons: A preliminary investigation of sensorless vibration monitoring applications. IEEE Trans. Ind. Appl. 35: 94-99

Schoen R R, Habetler T G, Kamran F, Bartheld R G 1995 Motor bearing damage detection using stator current monitoring. IEEE Trans. Ind. Appl. 31: 1274-1279

Yazıcı B, Kliman G B 1999 An adaptive statistical time-frequency method for detection of broken bars and bearing faults in motors using stator current. IEEE Trans. Ind. Appl. 35: 442-452 